TID-4500, UC-35
Nuclear Explosions - Peaceful Applications

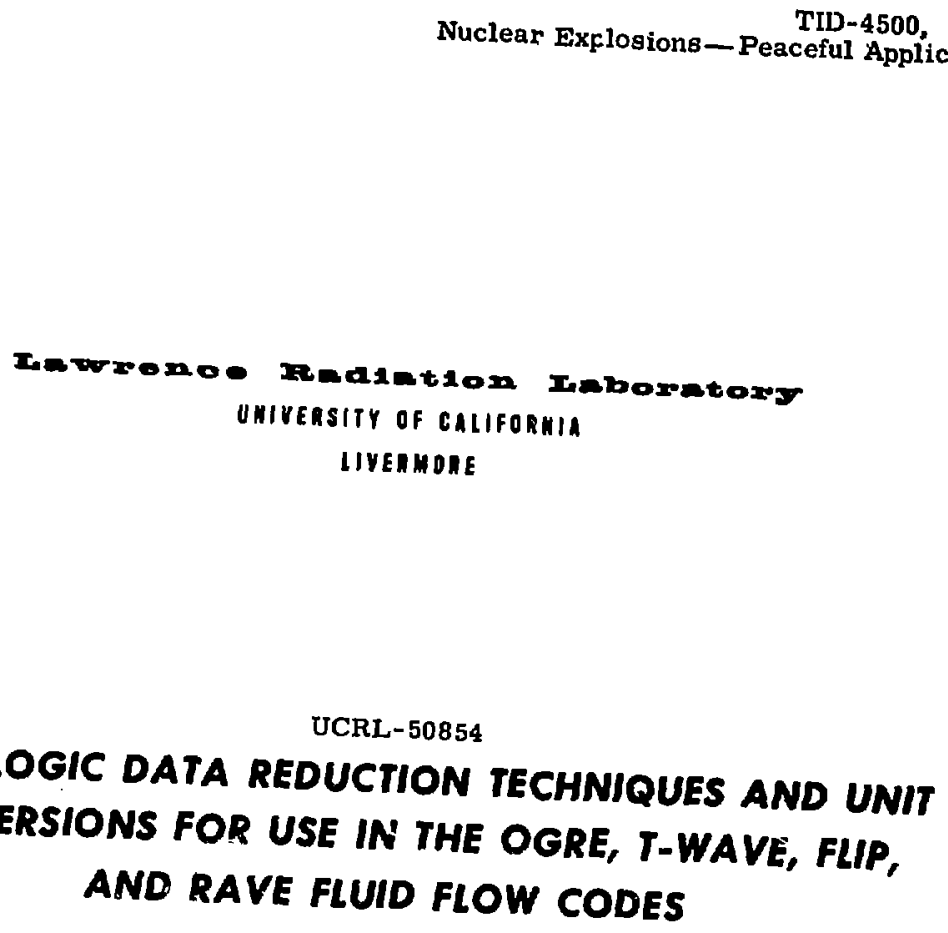

John A. Korver

\title{
HYDROLOGIC DATA REDUCTION TECHNIQUES AND UNIT CONVERSIONS FOR USE IN THE OGRE, T-WAVE, FUIP, AND RAVE FLUID FLOW CODES
}

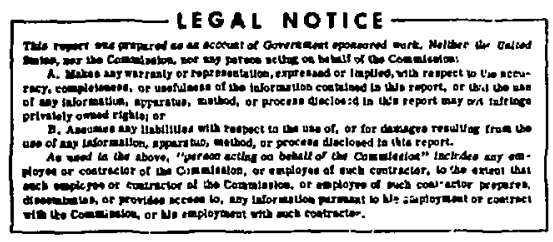

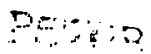




\section{HYDROLOGIC DATA REDUCTION TECHNIQUES AND UNIT CONVERSIONS FOR USE IN THE OGRE, T-WAVE, FLIP, AND RAVE FLUID FLOW CODES}

\section{Introduction}

Essentially all the hydrologic data used in the fluid flow codes come from hydrologic tests, geophysical logs and core studies. The hydrologic tests are used to determine $\mathrm{kH}$, the permeability-thickness product, while logs and core studies are used to determine porosity and producing intervals in the well. The hydrologic tests consist of either drawing down the fluid level from a constant depth or at a constant rate, or injecting fluid at a constant rate and then observing the recovery rate. Results frolin these tests are then used to determine the kII product.

Several methods are used in analyzing these data to arrive at a $\mathrm{kH}$ product. The method employed here is based on a technique described by Witherspoon et al. 1 This is the method presently used at Lawrence Radiation Laboratory.

For most drawdown tests, water is "bailed" or swabbed through tubing from a constant depth for a certain length of time. During this time the swab depth, the amount of fluid removed on each swab cycle and the time are recorded.

A rough field calcuiation of the $\mathrm{kH}$ product is made after each swab cycle. These calculations can be used as an index of how long the test should be continued since the successive $\mathrm{kH}$ products will approach a constant value as the test progresses.

Since the swab depths are estimated by the swab unit operator and the static fluid level is determined from the subsequent recovery test, these field-calculated $\mathrm{kH}$ products are considered to be only approximate. Table 1 illustrates the format for collecting field data." After the test has ended final recalculations are made using pressure and temperature bombs inserted in the well in conjunction with the production packers. Water levels at the beginning and end of each swab cycle can be calculated from the pressure data, and the fluid viscosity can be obtained from the temperature data.

The recovery following a swabbing test is monitored by logging the fluid level as a function of time. This is most commonly done with a logging unit designed by the U.S. Geological Survey (USGS) and equipped with an ohmmeter and a two-wire probe which records when the probe contacts the fluid. Both Birdwell and Schlumberger have similar tools. Fluid levels are recorded until the level has returaed to near the static, or pretest,

\footnotetext{
Tables 1 and 2 and Fig. 1 are taken from Ref. 2.
} 
condition. This time, in most cases, is about the drawdown portion of the test. Table 2 ilone and one-half times that consumed during lustrates the form of the recovery data.

Table 1. GB-3 swab togt No, 3.

Date: 9/1/69

Interval tested: 3580 to $3699 \mathrm{ft}$

\begin{tabular}{|c|c|c|c|c|c|c|c|c|c|}
\hline $\begin{array}{l}\text { Run } \\
\text { No. }\end{array}$ & $\begin{array}{l}\text { Clock } \\
\text { time }\end{array}$ & $\sum_{(\min )} \Delta t$ & $\begin{array}{l}\text { Staff } \\
\text { gauge } \\
\text { (ft) }\end{array}$ & $\underset{(\mathrm{gal})}{\Delta \mathrm{q}}$ & $\begin{array}{c}\Delta q / \Delta t \\
(g a 1 / \\
m i n)\end{array}$ & $\sum_{(\mathrm{gal} / \mathrm{min})} \frac{\Delta \mathrm{q}}{\Delta \mathrm{t}}$ & $\begin{array}{l}\text { Swab } \\
\text { depth } \\
\text { (ft) }\end{array}$ & $\begin{array}{l}\text { Water } \\
\text { level } \\
\text { (ft) }\end{array}$ & $\begin{array}{c}\mathbf{k H}^{\mathbf{a}} \\
(\mathbf{m d}-\mathbf{f t})\end{array}$ \\
\hline 1 & 1431 & 0 & & & & & 1200 & 0 & \\
\hline 2 & 1439 & 8 & & & & & 1500 & 300 & \\
\hline 3 & 1453 & 22 & & & & & 1800 & 400 & \\
\hline 4 & 1504 & 33 & & & & & 1900 & 550 & \\
\hline 5 & 1515 & 44 & & & & & 2000 & 700 & \\
\hline 6 & 1535 & 64 & & & & & 2100 & 900 & \\
\hline 7 & 1546 & 75 & & & & & 2200 & 1000 & \\
\hline 8 & 1600 & 89 & & & & & 2200 & 1100 & \\
\hline 9 & 1613 & 102 & & & & & 2400 & 1200 & \\
\hline 10 & 1628 & 117 & & & & & 2500 & 1300 & \\
\hline 11 & 1638 & 127 & & & & & 2600 & 1500 & \\
\hline 12 & 1650 & 139 & & & & & 2600 & 1500 & \\
\hline 13 & 1715 & 0 & 0.83 & 0 & 0 & 0 & 2700 & 1600 & \\
\hline 14 & 1730 & 15 & 1.02 & 111.7 & 7.44 & 7.44 & 2700 & 1650 & $16.59^{\mathrm{a}}$ \\
\hline 15 & 1745 & 30 & 1.28 & 152.9 & 10.19 & 17.63 & 2700 & 1650 & 39.32 \\
\hline 16 & 1800 & 45 & 1.52 & 141.1 & 9.02 & 26.65 & 2700 & 1700 & 59.43 \\
\hline 17 & 1815 & 60 & 1.75 & 135.2 & 7.84 & 34.49 & 2700 & 1750 & 76.91 \\
\hline 18 & 1830 & 75 & 1.95 & 117.6 & 5.88 & 40.37 & 2700 & & 90.03 \\
\hline 19 & 1848 & 93 & 2.10 & 88.2 & 4.90 & 45.27 & 2700 & 1800 & 100.95 \\
\hline 30 & 1858 & 103 & 2.29 & 117.7 & 11.17 & 56.44 & 2700 & $: 800$ & 125.86 \\
\hline 21 & 1908 & 113 & 2.47 & 105.8 & 8.23 & 64.67 & 2700 & 1800 & 144.21 \\
\hline 22 & 1920 & 125 & 2.61 & 82.3 & 7.06 & 71.73 & 2700 & 3800 & 159.96 \\
\hline 23 & 1930 & 135 & 2.73 & 70.6 & 7.06 & 79.79 & 2700 & 1800 & 183.58 \\
\hline 24 & 1941 & 146 & 2.85 & 70.6 & 6.41 & 85.20 & 2700 & 1800 & 190.00 \\
\hline 25 & 1952 & 157 & 3.00 & 88.2 & 8.02 & 93.22 & 2700 & 1800 & 207.88 \\
\hline 26 & 2002 & 167 & 3.10 & 58.8 & 5.88 & 99.10 & 2700 & & 220.99 \\
\hline 27 & 2013 & 178 & 3.25 & 88.2 & 8.02 & 107.12 & 2700 & 1800 & 238.88 \\
\hline 28 & 2033 & 188 & 3.36 & 64.7 & 6.47 & 113.59 & 2700 & & 253.31 \\
\hline 29 & 2034 & 199 & 3.45 & 52.9 & 4.81 & 118.40 & 2700 & & 264.03 \\
\hline
\end{tabular}

${ }^{2}$ These values were omilted in UCRL-50812 and were replaced by refined laboratory calculations. 
Table 2. GB-3 recovery test.

Date: $9 / 1-9 / 2 / 69$

$t_{0}=199 \mathrm{~min}$

\begin{tabular}{|c|c|c|c|c|c|c|c|}
\hline $\begin{array}{l}\text { Clock } \\
\text { time }\end{array}$ & $\underset{(\min )}{\Delta t}$ & $\begin{array}{l}\text { Water } \\
\text { level } \\
\text { (ft) }\end{array}$ & $\frac{t_{0}+\Delta t}{\Delta t}$ & $\begin{array}{l}\text { Clock } \\
\text { time }\end{array}$ & $\underset{(\min )}{\Delta t}$ & $\begin{array}{c}\text { Water } \\
\text { level } \\
\text { (ft) }\end{array}$ & $\frac{t_{0}+\Delta t}{\Delta t}$ \\
\hline 2152 & 78 & 1912 & 3.550 & 0400 & 446 & 1246 & 1.446 \\
\hline 2204 & 90 & 1847 & 3.210 & 0500 & 506 & 1221 & 1.394 \\
\hline 2206 & 92 & 1837 & 3.163 & 0550 & 556 & 1206 & 1.358 \\
\hline 2209 & 95 & 1821 & 3.095 & 0624 & 590 & 1198 & 1.337 \\
\hline 2213 & 99 & 1804 & 3.001 & \multicolumn{4}{|c|}{ Injected 100 gal water } \\
\hline 2221 & $10^{\prime}$ & 1771 & 2.860 & 0701 & 627 & 1083 & 1.314 \\
\hline 2229 & 115 & 1738 & 2.731 & 0704 & 630 & 1084 & 1.313 \\
\hline 2238 & 124 & 1706 & 2.605 & 0707 & 633 & 1085 & 1.313 \\
\hline 2248 & 134 & 1673 & 2.486 & 0710 & 636 & 1086 & 1.312 \\
\hline 2258 & 144 & 1641 & 2.382 & 0713 & 639 & 1087 & 1.311 \\
\hline 2309 & 155 & $i 607$ & 2.284 & 0716 & 642 & 1089 & 1.310 \\
\hline 23.21 & 167 & 1575 & 2.192 & 0719 & 645 & 1090 & 1.308 \\
\hline 2334 & 180 & 1542 & 2.105 & 0724 & 650 & 1092 & 1.306 \\
\hline 2348 & 194 & 1509 & 2.027 & 0731 & 657 & 1094 & 1.303 \\
\hline 0005 & 211 & 1476 & 1.943 & 0738 & 661 & 1096 & 1.300 \\
\hline 00 zs & 229 & 1442 & 1.869 & 0743 & 669 & 1097 & 1.297 \\
\hline 0043 & 249 & 1410 & 1.799 & 0753 & 679 & 1100 & 1.293 \\
\hline 0108 & 274 & 1378 & 1.726 & 0804 & 690 & 1104 & 1.289 \\
\hline 0137 & 303 & 1345 & 1.657 & 0824 & 710 & 1108 & 1.280 \\
\hline 0213 & 339 & 1312 & 1.587 & 0844 & 730 & 1112 & 1.273 \\
\hline 0300 & 386 & 1279 & 1.516 & & & & \\
\hline
\end{tabular}

\section{Calculation of $\mathbf{k H}$}

The formula used for determining $\mathrm{kH}$ from the drawdown data is

$$
\mathrm{kH}=\frac{\mu \Sigma \frac{\Delta q}{\Delta t}}{1.791 \times 10^{-4} \Delta H}
$$

where

$\mathrm{kHH}$ is the permeability-thickness product (md-fi),

$\mu$ is the fluid viscosity (cp),

$\Sigma \frac{\Delta q}{\Delta t}$ is the summation of the production rates (gal $/ \mathrm{min}$ ), $\Delta H$.is the drawdown from the static head ( $\mathrm{ft}$ ), and $1.791 \times 10^{-4}$ is a unit conversion factor. The formula used for determining $\mathrm{kH}$ from the recovery data is

$$
\mathrm{kH}=\frac{1.151 \mu \frac{\overline{\Delta q}}{\Delta \mathrm{q}^{-}}}{8.953 \times 10^{-5} \Delta \mathrm{H}_{10}}
$$


1.151 is the slope of the dimensionless pressure over dimensionless time for time sufficiently large,

$\overline{\Delta q} / \Delta t$ is the average production rate during swabbing (gal/min), $\Delta \mathrm{H}_{10}$ is the change in head over one log cycle of time (ft),

$8.953 \times 10^{-5}$ is the unit conversion factor, and

$\mu$ is the fluid viscosity (cp). back to static conditions. Since it is often not practical to monitor the fluid levels for long times, the process may be speeded up by "slugging" the well with enough fluid to raise the level above static. With a few additional observations of the declining water level, extrapoiation to $\left(t_{0}+\Delta t\right) / \Delta t$ $=1$ will give a fairly accurate value of the static level. This level is used in the swabbing equation to determine $\Delta H$.

To obtain $\Delta \mathrm{H}_{10}$, a straight line is drawn from the static level through the last few

To use this formula it is necessary to con- . data points and extended across one $\log$ struct a plot, as shown in Fig. 1, where $t_{0}$ is the time since swabbing started, $\Delta t$ is the time since swabbing stopped, and $\mathrm{H}$ is the depth of the water. When the log of cycle. Then $\Delta \mathrm{H}_{10}$ is the difference in water levels over one log cycle. In general, lower $\mathrm{kH}$ values are obtained from the recovery data than from the swab data.

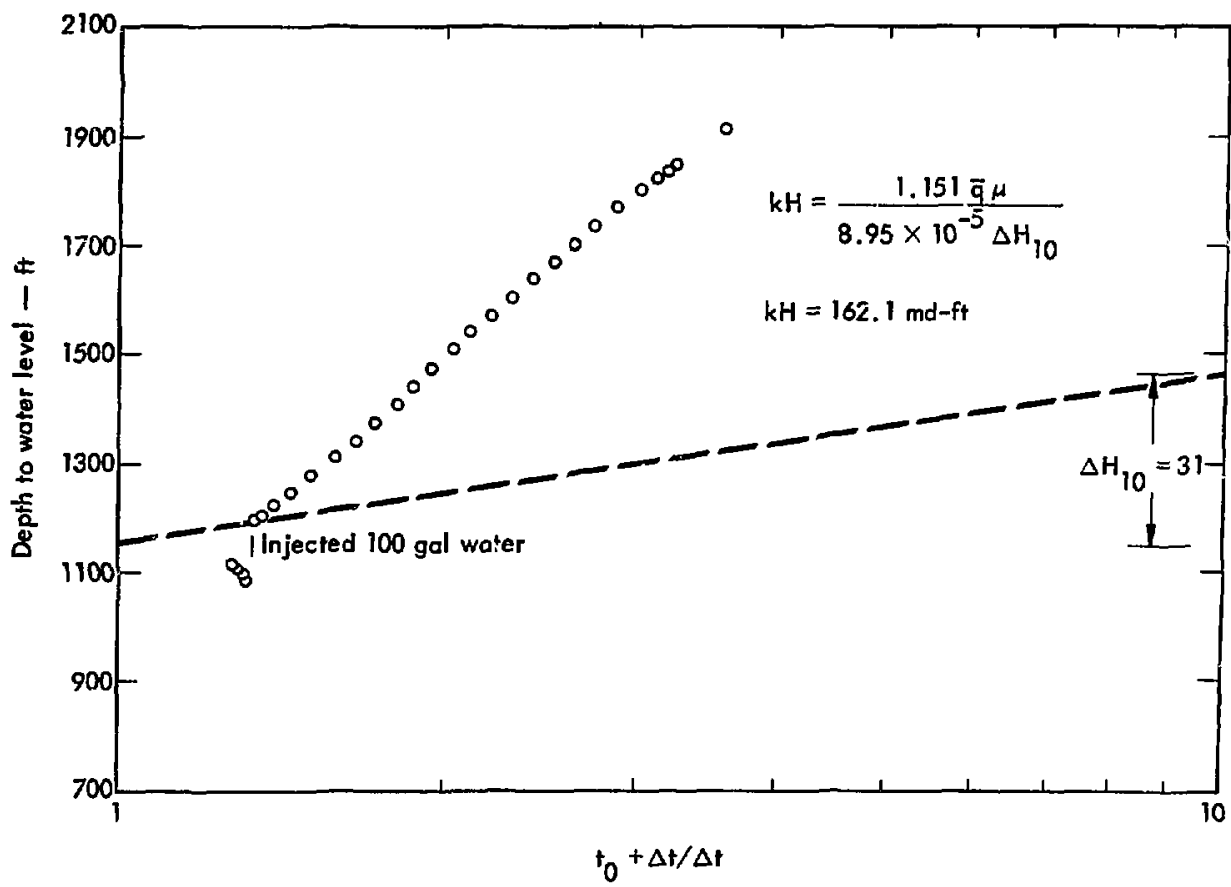

Fig. 1. GB-3 water level recovery. 


\section{Unit Conversions}

In the fluid flow codes, units of permeability are used which depend on the form of the velocity equations in each code. The one-dimensional, incompressible flow codes T-WAVE, ${ }^{3}$ RAVE, $^{4}$ and FIIP ${ }^{5}$ are based on the following form of the velocity equation:

$$
Y=-\frac{k}{\phi}\left(\frac{\partial h}{\partial r}\right)
$$

where

$$
\begin{aligned}
& \phi \text { is the fractional porosity } \\
& \text { (dimensionless), } \\
& \frac{\partial h}{\partial r} \text { is the hydraulic gradient } \\
& \text { (dimensionless), and } \\
& V \text { is the hurizontal velocity } \\
& \text { (distance L/time t). }
\end{aligned}
$$

The permeability $k$, then, has the units of velocity, that is, distance per unit timé. The usual units for T-WAVE and RAVE are $\mathrm{ft} / \mathrm{min}$, and for FLIP, $\mathrm{ft} / \mathrm{sec}$.

The form of the velocity equations in OGRE, ${ }^{6}$ a two-dimensional, compressible flow code, is

$$
V=-\frac{k}{\mu}(\nabla P+\nabla \gamma)
$$

where

$\mu$ is t'je viscosity (mass $M /$ distance $L \times$ time $t$ ), and

$\nabla P$ and $\nabla \gamma$ are pressure gradients (mass) area $x$ time $M / L^{2} t^{2}$ ).

The permeability $k$, then, hes the units of area $L^{2}$. Tne usual units in OGRE are $\mathrm{ft}^{2}$.

If the permeability is determined by the method outlined in the beginning of this report, it will be reported as a permeability-thickness product, or $\mathrm{kH}$, in units of $\mathrm{md}-\mathrm{ft}$. By dividing this product by the effective producing thickness, a permeability in rnillidarcies results. This may be converted to velocity or area units by the following relationship:

$$
\begin{aligned}
& 1 \text { millidarcy }=3.171 \times 10^{-8} \mathrm{ft} / \mathrm{sec} \\
&=1.903 \times 10^{-6} \mathrm{ft} / \mathrm{min} \\
&(\mathrm{T}-\mathrm{WAVE}, \mathrm{RAVE}) \\
&=1.062 \times 10^{-14} \mathrm{ft}^{2} \\
& \text { (OGRE) }
\end{aligned}
$$

If the permeability is determined by the U.S. Geological Survey, Water Resources Branch, it will normally be reported as Transmissivity, $T$, or sometimes as Relative Specific Capacity, $R_{s c}$. Sometimes both values are reported in which case, as will be explained later, the use of the transmissivity value is recommended. (Transmissivity replaces the former term, Coefficient of Transmissibility.)

Transmissivity $T$, which is used in the field and is uncorrected for density and viscosity, is usually reported in units of gallons/day/foot of drawdown (gpd/ft). However, the USGS plans to revise its standard hydrological terminology, and $T$ may appear in more recent data in units of meters ${ }^{2} /$ day.

$T$ is defined as

$$
\mathrm{T}=\mathrm{Kb}
$$

where

$\mathrm{K}$ is the hydraulic conductivity in

$$
\begin{aligned}
& \mathrm{gal} / \text { day } / \mathrm{ft}^{2} \text { (gpd/ft } \mathrm{ft}^{2} \text { or meters/day } \\
& \text { ( } \mathrm{m} / \text { day), aidd } \\
& \mathrm{b} \text { is the aquifer thickness in feet or } \\
& \text { meters. }
\end{aligned}
$$

The term $\mathrm{Kb}$ is similar to (but not identical with) the $\mathrm{kH}$ product. 
Since $T / b$ can be expressed in units of velocity, conversion of $T$ for use in FLIP, T-WAVE, and RAVE is straightforward. The relationships are as follows:

$$
\begin{aligned}
& \frac{T}{b}\left(\frac{g p d}{\mathrm{ft}^{2}}\right) \times 9.28 \times 10^{-5}=\mathrm{ft} / \mathrm{min} \\
& \frac{T}{b}\left(\frac{g p d}{\mathrm{ft}^{2}}\right) \times 1.547 \times 10^{-6}=\mathrm{ft} / \mathrm{sec} \\
& \left(\frac{T}{\mathrm{~b}} \frac{\mathrm{m}^{2}}{\mathrm{~m} d a y}\right) \times 7.475 \times 10^{-3}=\mathrm{ft} / \mathrm{min} \\
& \left(\frac{T}{\mathrm{~b}} \frac{\mathrm{m}^{2}}{\mathrm{~m} \text { day }}\right) \times 1.246 \times 10^{-4}=\mathrm{ft} / \mathrm{sec} .
\end{aligned}
$$

For conversion to units of area, necessary for OGRE, the following relationships hold:

$$
\begin{aligned}
& \frac{T}{b}\left(\frac{\mathrm{gpd}}{\mathrm{ft}^{2}}\right) \times 5.180 \times 10^{-13}=\mathrm{ft}^{2} \\
& \frac{T}{b}\left(\frac{\mathrm{m}^{2}}{\mathrm{~m} \text { day }}\right) \times 1.272 \times 10^{-1 i}=\mathrm{ft}^{2}
\end{aligned}
$$

As part of its program to revise its hydrological terminology, the USGS is abandoning the reporting of hydrologic results in terms of Relative Specitic Cepacity. This term evolved from the need to make short-duration recovery tests in wells on Pahute Mesa at the Nevada Test Site in connection with mining operations below the water table. The usefulness of the term is in question since it has not been shown to be applicable to any other location. Two other factors alsu show it to be of doubtful value: (1) groundwater flow under Pahute Mesa is largely fracture-controlled, and (2) the tests are so short ( $5 \mathrm{~min})$ that steadystate conditions cannot be assumed. In fact, an examination of the formula for determining $\mathbf{R}_{\mathbf{B C}}$ shows that its value cannot be constant until the aquifer has almost fully recovered.

in conclusion, too many factors must be assumed to make the use of this term practical in most cases. It is recommended, then, that only data reported by the USGS in terms of Transmissivity or millidarcies be used for the fluid flow codes. 


\section{References}

1. P. A. Witherspoon, et al., "Interpretation of Aquifer Gas Storage Conditions from Water Pumping Tests," American Gas Association New York Monograph NS-38, Chapter 1, 1967. (Prepared at the University of California, Berkeley.)

2. J. A. Korver, "Gasbuggy Postshot Hydrologic Investigations in GB-3," Lawrence Radiation Laboratory, Livermore, UCRL-50812, March 9, 1970.

3. J. A. Korver, "T-WAVE-A Computer Code for Analyzing the Nonsteady Gravity Decay of a Groundwater Anomaly," Lawrence Radiation Laboratory, Livermore, UCRL-50830, March 6, 1970.

4. J. A. Korver, "RAVE-A Computer Code for Analyzing Nonsteady Incompressible Flow of a Fluid Into or Out of a Nuclear Chimney," Lawrence Radiation Laboratory, Livermore, UCRL-50828, February 25, 1970.

5. J.A. Korver, "The FLIP Code: Fluid Injection Program," Lawrence Radiation Laboratory, Livermore, UCRL-50506, October 15, 1968.

6. J. A. Korver, "The OGRE Code-A Two-Dimensional Numerical Model of the Transient Flow of One or Two Compressible Fluids through Confined Porous Media," Lawrence Radiation Laboratory, Livermore, iTCRI,-50820, February 11, 1970. 